\title{
The potential negative impact of antibiotic pack on antibiotic stewardship in primary care in Switzerland: a modelling study
}

\author{
Julia Füri ${ }^{1,2}$, Andreas Widmer ${ }^{1,3}$, Delia Bornand ${ }^{4}$, Christoph Berger ${ }^{5,6}$, Benedikt Huttner ${ }^{7,8}$ and Julia Anna Bielicki ${ }^{1,2,3^{*}}$
}

\begin{abstract}
Background: In Switzerland, oral antibiotics are dispensed in packs rather than by exact pill-count. We investigated whether available packs support compliance with recommended primary care treatment regimens for common infections in children and adults.

Methods: Hospital-based guidelines for oral community -based treatment of acute otitis media, sinusitis, tonsillopharyngitis, community-acquired pneumonia and afebrile urinary tract infection were identified in 2017 in an iterative process by contacting hospital pharmacists and infectious diseases specialists. Furthermore, newly available national guidelines published in 2019 were reviewed. Available pack sizes for recommended solid, dispersible and liquid antibiotic formulations were retrieved from the Swiss pharmaceutical register and compared with recommended regimens to determine optimal (no leftovers) and adequate (optimal +/- one dose) matches.

Results: A large variety of recommended regimens were identified. For adults, optimal and adequate packs were available for 25/70 (36\%) and 8/70 (11\%) regimens, respectively. Pack-regimen matching was better for WHO Watch (optimal: 15/24, 63\%) than Access antibiotics (optimal: 7/39, 18\%). For the four paediatric weight-examples and 42 regimens involving child-appropriate formulations, optimal and adequate packs were available for only 14/168 (8\%) and $27 / 168(16 \%)$, respectively. Matching was better for older children with higher body and for longer treatment courses $>7$ days.

Conclusions: Fixed antibiotic packs often do not match recommended treatment regimens, especially for children, potentially resulting in longer than necessary treatments and leftover doses in the community. As part of national stewardship, a move to an exact pill-count system, including for child-appropriate solid formulations, should be considered.
\end{abstract}

Keywords: Antibiotic stewardship, Community prescribing, Children, Adults, Prescribing guidelines

\footnotetext{
* Correspondence: juliaanna.bielicki@ukbb.ch

'Division of Infectious Diseases and Hospital Epidemiology, University

Hospital Basel, Petersgraben 4, 4031 Basel, Switzerland

2Paediatric Pharmacology Group, University of Basel Children's Hospital, Basel, Switzerland

Full list of author information is available at the end of the article
}

C C The Author(s). 2020 Open Access This article is licensed under a Creative Commons Attribution 4.0 International License, which permits use, sharing, adaptation, distribution and reproduction in any medium or format, as long as you give appropriate credit to the original author(s) and the source, provide a link to the Creative Commons licence, and indicate if changes were made. The images or other third party material in this article are included in the article's Creative Commons licence, unless indicated otherwise in a credit line to the material. If material is not included in the article's Creative Commons licence and your intended use is not permitted by statutory regulation or exceeds the permitted use, you will need to obtain permission directly from the copyright holder. To view a copy of this licence, visit http://creativecommons.org/licenses/by/4.0/ The Creative Commons Public Domain Dedication waiver (http://creativecommons.org/publicdomain/zero/1.0/) applies to the data made available in this article, unless otherwise stated in a credit line to the data. 


\section{Background}

Antibiotic resistance is increasingly becoming a global challenge to human health [1]. The use of leftover prescribed antibiotics has been shown to be a source of self-medication and overuse of antibiotics, potentially driving resistance emergence and spread [2-4]. In Switzerland and many other countries, antibiotics are dispensed in fixed packs. Such dispensation practices appear to be a strong factor in determining possession of leftovers in the ambulatory setting [5]. A potential mismatch between clinical practice guidelines and packs could considerably influence the amount of leftover antibiotics, and therefore contribute to antibiotic misuse and overuse [69]. The trend towards shorter durations of antibiotic treatments could aggravate this problem if pack size remains unrevised especially for older antibiotics [10].

In 2017, the World Health Organisation (WHO) defined antibiotic groups (Access, Watch, Reserve) that are to be used globally for national stewardship based on their likely ecologic impact on antimicrobial resistance [11]. In 2019, a recommendation for at least $60 \%$ of all antibiotics used at a national level to be from the socalled Access group followed [12]. It is unclear whether there could be a differential pack-regimen mismatch for Access compared with other antibiotics, given that many Access antibiotics are older agents that came to market when longer treatment durations were favoured [10, 13]. This could potentially drive preferential prescribing of Watch antibiotics to support currently recommended shorter treatment durations.

We investigated whether antibiotic packs available in Switzerland correspond to, and therefore support compliance with, treatment regimens specified in clinical practice guidelines for common infections in children and adults treated in primary care. As a secondary objective we evaluated the types of antibiotics most commonly involved in mismatches with respect to the new WHO Access, Watch, Reserve (AWaRe) grouping of antibiotics for stewardship.

\section{Methods}

In Switzerland, a system of compulsory health insurance covers most healthcare costs. Non-profit insurers, approved by the government, offer a basic mandatory insurance and voluntary top-up plans covering special conditions or additional services [14]. Prescribed medicines from the "list of pharmaceutical specialties", such as oral antibiotics, are generally reimbursed by basic insurance $[15,16]$.

\section{Guidelines}

Five infections frequently treated with oral antibiotics in the primary care setting in children and adults (otitis media, sinusitis, tonsillopharyngitis, community-acquired pneumonia (CAP), afebrile urinary tract infections (UTI)) were selected for this study. For these, we collected hospital-based treatment guidelines in an iterative process during July 2017-November 2017 by (i) posting a request on the online forum of the Swiss association of Public Health Administration and Hospital Pharmacists, (ii) directly contacting infectious diseases specialists at selected centres and (iii) searching online for open access hospital guidelines.

We specifically focused on obtaining information from designated training hospitals for infectious diseases. Additional guidelines from non-training hospitals were also considered and included if their recommendations deviated. When national recommendations became available in 2019 for otitis media, sinusitis, tonsillopharyngitis and adult afebrile UTI, these were included [17]. We assume that a considerable proportion of prescribers is likely to be using local older recommendations during a transitional period as well as for CAP pending national guidance.

\section{Antibiotic formulations and packs}

All formulations, packs and brands for the antibiotics recommended in the identified guidelines were retrieved from Compendium ${ }^{\circ}$, the pharmaceutical register of all medications available in Switzerland, excluding those imported from foreign countries [18].

We divided oral formulations into 3 groups: solid (tablets, capsules), dispersible (tablets, granules) and liquid (suspension, powder for oral suspension). Only liquids were considered child-appropriate, because children younger than school age are unlikely to be able to swallow monolithic solid formulations [19]. Furthermore, solids and dispersible tablets are licensed only in patients weighing more than $40 \mathrm{~kg}$ in Switzerland, so their use would be considered off-label in young children. Slow release formulations were not included because of their absence of recommendation in the guidelines, with the exception of nitrofurantoin.

\section{Identification of recommended regimens}

Data on the following aspects of each regimen and infection were entered onto an online REDCap ${ }^{\text {Tw }}$ database: recommended drug, single dose, dosing frequency and duration of treatment, recommended first or second-line or in special instances (drug allergy) [20]. Recommendations for "simple urinary tract infection" were interpreted as only applicable to women.

We analysed all possible oral antibiotic regimens for all recommended active substances by infection: For adult patients, we calculated the required number of solid or dispersible dosing units per regimen. In cases of treatment duration ranges, the required number of dosing units for the minimal and maximal duration was determined and only the extremes were evaluated as no 
assumptions about the commonly selected durations were possible.

As paediatric prescribing in Switzerland is weightbased, we used four weight-examples to evaluate pack and regimen matches at body weights of $10 \mathrm{~kg}$ (corresponding to roughly 15 months of age), $15 \mathrm{~kg}$ (roughly 3.5 years), $20 \mathrm{~kg}$ (roughly 6 years) and $25 \mathrm{~kg}$ (roughly 8 years) [21].

For formulations with amoxicillin and enzyme inhibitor, all calculations were based on the amoxicillin content whereas for cotrimoxazole, we considered the total amount of both substances together. For paediatric amoxicillin/clavulanate use, we limited ourselves to $7: 1$ ratio formulations.

\section{Determination of matching of available packs and regimens}

Based on the above data, regimens were matched with available packs and were categorized into three groups: optimal match (no leftover doses for recommended regimen), adequate match (optimal $+/$ - one single dose compared to recommended regimen), no match $(+/-$ more than two doses compared to recommended regimen necessary to match pack). For children, we followed the same approach by calculating the total amount required for a treatment course for all identified regimens by weight-example. Pack-regimen matching was done as for adults but limited to child-appropriate liquid formulations. We assumed that dispensation of several packs, when required, would involve only one type of pack and formulation concentration. Combinations of different packs per drug were not considered.

\section{Matching patterns according to access and Watch WHO antibiotic groups}

We reviewed pack-regimen matching by Access and Watch groups as defined in the 2017 revision of the WHO Model list of Essential Medicines, considering only core Access antibiotics as part of the Access group [11]. Access-Watch antibiotics were included in the Watch group. Oral fosfomycin and cefuroxime were not listed and thus excluded from this analysis.

\section{Results}

\section{Guidelines}

For adults, 16 different hospitals provided guidelines, of which 14 were included in our study since they provided specific recommendations for the infections of interest (Additional file 1). Together with national guidelines, there were 11 different treatment guidelines for each infection with the exception of CAP with 10 guidelines and UTI in men with only six guidelines. For children, six hospitals (three university level and three regional hospitals) provided guidelines, all were included in our study. We were not able to obtain paediatric guidelines from the French part of Switzerland. All included guidelines contained recommendations for otitis media and tonsillopharyngitis. As updated national paediatric guidelines for UTI and CAP are not yet available, there were only six guidelines for these two infections, and treatment recommendations for sinusitis were only found in five guidelines.

\section{Treatment regimens}

For adults, 70 regimens involving 15 antibiotics differing in single dose, dosing frequency and duration were identified; some were only recommended as second-line treatment, for example in the context of penicillin allergy (Additional file 2). For children, 52 oral treatment regimens for 11 substances were identified (Additional file 2).

In general, we observed a big difference in the diversity of the recommendations between infections. In both adults and children, the greatest number of treatment regimens was identified for CAP (31 for adults, involving 7 different antibiotics with treatment durations of five to 10 days; 22 for children, involving 6 antibiotics with durations of three to 10 days). The number of regimens for sinusitis, acute otitis media and streptococcal tonsillopharyngitis was generally higher for adults than for children (32 versus 8,28 versus 11 and 21 versus 13 , respectively). As similar numbers of individual agents were involved, these differences generally were related to higher variability in combinations of single dose, dosing frequency and duration. In contrast, we found only nine different regimens for UTI in women and seven regimens for UTI in men. For afebrile urinary tract infection in children there was a bigger variety of 13 different regimens involving five antibiotics. Treatment durations for afebrile UTI were relatively short, ranging from one to 7 days depending on age, sex and antibiotic used.

\section{Available oral antibiotic formulations}

In total, fifteen antibiotics from the above regimens were of interest with solid and at least one liquid formulation being available for nine of these (no liquid formulations for norfloxacin, levofloxacin, moxifloxacin, doxycycline, fosfomycin and nitrofurantoin, Additional file 3). Correspondingly, paediatric guidelines only made recommendations for nitrofurantoin and doxycycline in children older than 8 years not covered by our weight-examples.

\section{Matching of recommended regimens and packs}

For adults, optimal packs were available for only 36\% $(25 / 70)$ of recommended regimens and for an additional $11 \%(8 / 70)$ packs were adequate (Table 1 and Additional file 2). For the remaining 53\% (37/70), no matching packs could be found. 
Table 1 Pack-antibiotic regimen matching (optimal and adequate) for adults

\begin{tabular}{|c|c|c|c|c|c|c|c|c|c|}
\hline \multicolumn{4}{|l|}{ Regimen } & \multirow[t]{2}{*}{ CAP } & \multirow{2}{*}{$\begin{array}{l}\text { Otitis } \\
\text { media }\end{array}$} & \multirow[t]{2}{*}{ Tonsillopharyngitis } & \multirow[t]{2}{*}{ Sinusitis } & \multirow{2}{*}{$\begin{array}{l}\text { UTI } \\
\text { women }\end{array}$} & \multirow{2}{*}{$\begin{array}{l}\text { UTI } \\
\text { men }\end{array}$} \\
\hline Substance & Single dose & $\mathrm{N}$ doses/day & Duration (in days) & & & & & & \\
\hline \multicolumn{10}{|l|}{ WHO group: ACCESS } \\
\hline \multirow[t]{7}{*}{ Amoxicillin } & $375 \mathrm{mg}$ & 3 & 5 & & & $15(+1)$ & & & \\
\hline & $500 \mathrm{mg}$ & 3 & 7 & & & & $21(-1)$ & & \\
\hline & 750 mg & 3 & 7 & $21(-1)$ & $21(-1)$ & & $21(-1)$ & & \\
\hline & $1000 \mathrm{mg}$ & 2 & 5 & 10 & & & $10^{\mathrm{a}}$ & & \\
\hline & $1000 \mathrm{mg}$ & 2 & 7 & 14 & & & $14^{\mathrm{a}}$ & & \\
\hline & 1000 mg & 3 & 5 & $15(-1)$ & $15(-1)^{\mathbf{a}}$ & & $15(-1)^{\mathbf{a}}$ & & \\
\hline & $1000 \mathrm{mg}$ & 3 & 7 & $21(-1)$ & & & $21(-1)$ & & \\
\hline \multirow[t]{4}{*}{ Amoxicillin/clavulanate } & $625 \mathrm{mg}$ & 3 & 3 & & & & & $9(+1)^{\mathbf{a}}$ & \\
\hline & $625 \mathrm{mg}$ & 3 & 7 & $21(-1)$ & $21(-1)$ & & $21(-1)$ & & \\
\hline & $1000 \mathrm{mg}$ & 2 & 10 & 20 & 20 & & 20 & & \\
\hline & $1000 \mathrm{mg}$ & 4 & 5 & & & & $20^{a}$ & & \\
\hline Doxycycline & $100 \mathrm{mg}$ & 2 & 5 & 10 & 10 & & $10^{\mathrm{a}}$ & & \\
\hline \multirow[t]{2}{*}{ Cotrimoxazole } & $960 \mathrm{mg}$ & 2 & 5 & & $10^{\mathrm{a}}$ & & 10 & & 10 \\
\hline & $960 \mathrm{mg}$ & 2 & 10 & & 20 & & & & \\
\hline \multicolumn{10}{|l|}{ WHO group: WATCH } \\
\hline \multirow[t]{2}{*}{ Azithromycin } & $500 \mathrm{mg}$ & 1 & 3 & & 3 & 3 & 3 & & \\
\hline & $500 \mathrm{mg}$ & 1 & 5 & & $5(+1)$ & $5(+1)$ & & & \\
\hline Ciprofloxacin & $500 \mathrm{mg}$ & 2 & 5 & & & & & & 10 \\
\hline \multirow[t]{4}{*}{ Clarithromycin } & $250 \mathrm{mg}$ & 2 & 7 & & 14 & & 14 & & \\
\hline & $250 \mathrm{mg}$ & 2 & 10 & & & 20 & & & \\
\hline & $500 \mathrm{mg}$ & 2 & 7 & 14 & 14 & & & & \\
\hline & $500 \mathrm{mg}$ & 2 & 10 & 20 & 20 & 20 & & & \\
\hline \multirow[t]{5}{*}{ Levofloxacin } & $500 \mathrm{mg}$ & 1 & 5 & 5 & & & 5 & & \\
\hline & $500 \mathrm{mg}$ & 1 & 7 & 7 & & & 7 & & \\
\hline & $500 \mathrm{mg}$ & 1 & 10 & & & & 10 & & \\
\hline & $500 \mathrm{mg}$ & 2 & 5 & 10 & & & & & \\
\hline & $500 \mathrm{mg}$ & 2 & 7 & 14 & & & & & \\
\hline \multirow[t]{3}{*}{ Moxifloxacin } & $400 \mathrm{mg}$ & 1 & 5 & 5 & & & & & \\
\hline & $400 \mathrm{mg}$ & 1 & 7 & 7 & & & 7 & & \\
\hline & $400 \mathrm{mg}$ & 1 & 10 & 10 & & & 10 & & \\
\hline Norfloxacin & $400 \mathrm{mg}$ & 2 & 3 & & & & & $6^{a}$ & \\
\hline \multicolumn{10}{|c|}{ WHO group: UNCLASSIFIED } \\
\hline \multirow[t]{2}{*}{ Cefuroxime } & $250 \mathrm{mg}$ & 2 & 7 & & 14 & & 14 & & \\
\hline & $500 \mathrm{mg}$ & 2 & 7 & 14 & 14 & & $14^{\mathrm{a}}$ & $14^{\mathrm{a}}$ & \\
\hline Fosfomycin & $3000 \mathrm{mg}$ & 1 & 1 & & & & & $1^{a}$ & \\
\hline
\end{tabular}

apart of the SSI-Guidelines (ssi.guidelines.ch)

$+1=$ optimized by adding a single dose; $-1=$ optimized by subtracting a single dose CAP Community-acquired pneumonia, UTI Urinary tract infection

The regimens are shown together with the number of dosing units required for that regimen. Antibiotics are listed alphabetically by WHO Access or Watch groups with unclassified antibiotics listed separately. Bold font indicates availability of an optimal pack for the listed antibiotic and regimen. Normal font indicates availability of an adequate pack for the listed antibiotic and regimen, meaning that matching could be achieved by adding or dropping a single dosing unit. Listed regimens represent $47.1 \%$ (33/70 regimens) for adults. All remaining regimens did not have matching optimal or adequate packs 
Antibiotics with optimal matching for all recommendations were oral fosfomycin, moxifloxacin and norfloxacin. Antibiotics without matching for any recommendations were clindamycin, nitrofurantoin and phenoxymethylpenicillin. For nine of 15 antibiotics $<50 \%$ optimal or adequate pack sizes existed for the recommended regimens. Amoxicillin packs matched only a small number of regimens (2/ 15 regimens, 13\%) as did those for amoxicillin/clavulanate (2/12 regimens, $17 \%)$, despite these two antibiotics having the highest diversity of regimens.

For children, we matched 42 treatment regimens of nine antibiotics with child-appropriate liquid formulations available for four weight-examples. Optimal packs existed only for $8 \%(14 / 168)$ of regimens, with adequate packs available for another $16 \%$ (27/168) (Tables 2, 3, 4, 5 and Additional file 2).

For the remaining 76\% (127/168), no matching packs could be found. We observed best matching for amoxicillin regimens $(4 / 28,14 \%)$. Despite three different available pack sizes for amoxicillin/clavulanate and 13 different regimens, only $12 \%(6 / 52)$ had optimal packs. We could not find any suitable packs for the considered weight-examples for ciprofloxacin, clarithromycin, phenoxymethylpenicillin and cotrimoxazole. For lighter and therefore younger children $(10 \mathrm{~kg}, 15 \mathrm{~kg})$ matching was poorer than for heavier older children $(20 \mathrm{~kg}, 25 \mathrm{~kg}$ ). Comparing optimal versus adequate packs, there were more optimal packs available for regimens with longer duration, especially in younger children.

\section{Matching according to the WHO AWaRe groups}

For adults, optimal and adequate packs existed for only $18 \%(7 / 39)$ and $18 \%(7 / 39)$ regimens involving Access antibiotics (Table 1 and Additional file 4). For the remaining 64\% (25/39) no matching packs could be found. In contrast optimal packs were available for $63 \%$ $(15 / 24)$ of regimens involving Watch antibiotics.

For children, a very low rate of optimal available packs was found for both groups (9\% in the Access group, 4\% in the Watch group, Tables 2, 3, 4, 5 and Additional file 4). We also observed a larger range of different regimens $(N=12-52)$ for Access antibiotics than for Watch antibiotics $(N=4-12)$.

\section{Discussion}

Our analysis of pack-regimen matching showed an important mismatch between recommended oral regimens for infections commonly treated in the community setting and available pack sizes for antibiotics in Switzerland.

For adults, a suitable pack could be found for only $36 \%$ of the considered regimens, and for childappropriate formulations this rate was even lower at $8 \%$ based on four weight-examples. In adults, all antibiotics with high rates of suitable packs were from the WHO Watch group [10]. This is an alarming fact from the perspective of antibiotic stewardship: Dispensing of Watch antibiotics in Switzerland seems paradoxically easier than dispensing of Access antibiotics, with better packregimen matching.

Table 2 Pack-antibiotic regimen matching (optimal and adequate) in children weighing $10 \mathrm{~kg}$ ( $\approx 15$ months of age)

\begin{tabular}{|c|c|c|c|c|c|c|c|c|}
\hline \multicolumn{4}{|l|}{ Regimen } & \multirow[t]{2}{*}{ CAP } & \multirow{2}{*}{$\begin{array}{l}\text { Otitis } \\
\text { media }\end{array}$} & \multirow[t]{2}{*}{ Tonsillopharyngitis } & \multirow[t]{2}{*}{ Sinusitis } & \multirow{2}{*}{$\begin{array}{l}\text { Afebrile } \\
\text { UTI }\end{array}$} \\
\hline Substance & Single dose & $\mathrm{N}$ doses/day & Duration (in days) & & & & & \\
\hline \multicolumn{9}{|l|}{ WHO group: ACCESS } \\
\hline Amoxicillin & $25 \mathrm{mg} / \mathrm{kg}$ & 2 & 10 & 1 & $1^{a}$ & & $1^{a}$ & \\
\hline \multirow[t]{5}{*}{ Amoxicillin/clavulanate } & 25 mg/kg & 2 & 5 & & & & & $0.89(+1)$ \\
\hline & $26.7 \mathrm{mg} / \mathrm{kg}$ & 3 & 7 & 1 & & & & \\
\hline & 40 mg/kg & 2 & 3 & & & & & $0.86(+1)$ \\
\hline & $40 \mathrm{mg} / \mathrm{kg}$ & 2 & 7 & 1 & & & & \\
\hline & $40 \mathrm{mg} / \mathrm{kg}$ & 2 & 14 & & & & $1^{a}$ & \\
\hline Clindamycin & 7 mg/kg & 3 & 6 & & & $1.05(-1)^{\mathbf{a}}$ & & \\
\hline \multicolumn{9}{|l|}{ WHO group: WATCH } \\
\hline Azithromycin & 10 mg/kg & 1 & 5 & & & $0.83(+1)$ & & \\
\hline \multicolumn{9}{|c|}{ WHO group: UNCLASSIFIED } \\
\hline \multirow[t]{2}{*}{ Cefuroxime } & 15 mg/kg & 2 & 5 & $0.86(+1)$ & $0.86(+1)^{\mathbf{a}}$ & $0.86(+1)$ & & $0.86(+1)$ \\
\hline & 15 mg/kg & 2 & 6 & & & $1.03(-1)^{\mathbf{a}}$ & & \\
\hline
\end{tabular}

${ }^{a}$ part of the SSI-Guidelines (ssi.guidelines.ch)

+1 = optimized by adding a single dose; -1 = optimized by subtracting a single dose

CAP Community-acquired pneumonia, UTI Urinary tract infection

The regimens are shown together with the number of dosing units required for that regimen. Antibiotics are listed alphabetically by WHO Access or Watch groups with unclassified antibiotics listed separately. Bold font indicates availability of an optimal pack for the listed antibiotic and regimen. Normal font indicates availability of an adequate pack for the listed antibiotic and regimen, meaning that matching could be achieved by adding or dropping a single dosing unit to the regimen or leftovers of < one single dosing unit. Listed regimens represent $24.4 \%$ (10/42 regimens) in this weight-example. All remaining regimens did not have matching optimal or adequate packs 
Table 3 Pack-antibiotic regimen matching (optimal and adequate) in children weighing $15 \mathrm{~kg}$ ( $\approx 3.5$ years of age)

\begin{tabular}{|c|c|c|c|c|c|c|c|c|}
\hline \multicolumn{4}{|l|}{ Regimen } & \multirow[t]{2}{*}{ CAP } & \multirow{2}{*}{$\begin{array}{l}\text { Otitis } \\
\text { media }\end{array}$} & \multirow[t]{2}{*}{ Tonsillopharyngitis } & \multirow[t]{2}{*}{ Sinusitis } & \multirow{2}{*}{$\begin{array}{l}\text { Afebrile } \\
\text { UTI }\end{array}$} \\
\hline Substance & Single dose & $\mathrm{N}$ doses/day & Duration (in days) & & & & & \\
\hline \multicolumn{9}{|l|}{ WHO group: ACCESS } \\
\hline Amoxicillin & 25 mg/kg & 2 & 7 & & & $1.05(-1)$ & & \\
\hline \multirow[t]{2}{*}{ Amoxicillin/clavulanate } & 25 mg/kg & 2 & 3 & & & & & $0.80(+1)$ \\
\hline & $25 \mathrm{mg} / \mathrm{kg}$ & 2 & 7 & 0.94 & & & & \\
\hline \multicolumn{9}{|l|}{ WHO group: WATCH } \\
\hline \multirow[t]{2}{*}{ Azithromycin } & 10 mg/kg & 1 & 3 & $0.75(+1)$ & $0.75(+1)$ & & & \\
\hline & $10 \mathrm{mg} / \mathrm{kg}$ & 1 & 5 & & & $1.25(-1)$ & & \\
\hline \multicolumn{9}{|c|}{ WHO group: UNCLASSIFIED } \\
\hline Cefuroxime & 15 mg/kg & 2 & 7 & $1.8(+1)$ & & & & \\
\hline
\end{tabular}

$+1=$ optimized by adding a single dose; $-1=$ optimized by subtracting a single dose

CAP Community-acquired pneumonia, UTI Urinary tract infection

The regimens are shown together with the number of dosing units required for that regimen. Antibiotics are listed alphabetically by WHO Access or Watch groups with unclassified antibiotics listed separately. Bold font indicates availability of an optimal pack for the listed antibiotic and regimen. Normal font indicates availability of an adequate pack for the listed antibiotic and regimen, meaning that matching could be achieved by adding or dropping a single dosing unit to the regimen or leftovers of < one single dosing unit. Listed regimens represent $14.6 \%$ (6/42 regimens) in this weight-example. All remaining regimens did not have matching optimal or adequate packs

Table 4 Pack-antibiotic regimen matching (optimal and adequate) in children weighing $20 \mathrm{~kg}$ ( $\approx 6$ years of age)

\begin{tabular}{|c|c|c|c|c|c|c|c|c|}
\hline \multicolumn{4}{|l|}{ Regimen } & \multirow[t]{2}{*}{ CAP } & \multirow{2}{*}{$\begin{array}{l}\text { Otitis } \\
\text { media }\end{array}$} & \multirow[t]{2}{*}{ Tonsillopharyngitis } & \multirow[t]{2}{*}{ Sinusitis } & \multirow{2}{*}{$\begin{array}{l}\text { Afebrile } \\
\text { UTI }\end{array}$} \\
\hline Substance & Single dose & $\mathrm{N}$ doses/day & Duration (in days) & & & & & \\
\hline \multicolumn{9}{|l|}{ WHO group: ACCESS } \\
\hline \multirow[t]{2}{*}{ Amoxicillin } & $25 \mathrm{mg} / \mathrm{kg}$ & 2 & 5 & & $1^{\mathrm{a}}$ & & & \\
\hline & $25 \mathrm{mg} / \mathrm{kg}$ & 2 & 10 & 2 & $2^{\mathrm{a}}$ & & $2^{a}$ & \\
\hline \multirow[t]{6}{*}{ Amoxicillin/clavulanate } & $25 \mathrm{mg} / \mathrm{kg}$ & 2 & 5 & & & & & $0.89(+1)$ \\
\hline & $26.7 \mathrm{mg} / \mathrm{kg}$ & 3 & 3 & & & & & $0.86(+1)$ \\
\hline & $26.7 \mathrm{mg} / \mathrm{kg}$ & 3 & 7 & 1 & & & & \\
\hline & $40 \mathrm{mg} / \mathrm{kg}$ & 2 & 3 & & & & & $0.86(+1)$ \\
\hline & $40 \mathrm{mg} / \mathrm{kg}$ & 2 & 7 & 1 & & & & \\
\hline & $40 \mathrm{mg} / \mathrm{kg}$ & 2 & 14 & & & & $2^{a}$ & \\
\hline \multirow[t]{2}{*}{ Clindamycin } & $7 \mathrm{mg} / \mathrm{kg}$ & 3 & 6 & & & $2.1(-1)^{\mathbf{a}}$ & & \\
\hline & $10 \mathrm{mg} / \mathrm{kg}$ & 3 & 10 & & & 5 & & \\
\hline \multicolumn{9}{|l|}{ WHO group: WATCH } \\
\hline \multirow[t]{2}{*}{ Azithromycin } & $10 \mathrm{mg} / \mathrm{kg}$ & 1 & 3 & 1 & 1 & & & \\
\hline & $10 \mathrm{mg} / \mathrm{kg}$ & 1 & 5 & & & $0.83(+1)$ & & \\
\hline \multicolumn{9}{|c|}{ WHO group: UNCLASSIFIED } \\
\hline \multirow[t]{3}{*}{ Cefuroxime } & $15 \mathrm{mg} / \mathrm{kg}$ & 2 & 5 & $1.7(+1)$ & $1.7(+1)^{\mathbf{a}}$ & $1.7(+1)$ & & $1.7(+1)$ \\
\hline & $15 \mathrm{mg} / \mathrm{kg}$ & 2 & 6 & & & $2.06(-1)^{\mathbf{a}}$ & & \\
\hline & $15 \mathrm{mg} / \mathrm{kg}$ & 2 & 14 & & & & $4.8(+1)^{\mathbf{a}}$ & \\
\hline
\end{tabular}

apart of the SSI-Guidelines (ssi.guidelines.ch)

$+1=$ optimized by adding a single dose; $-1=$ optimized by subtracting a single dose

CAP Community-acquired pneumonia, UTI Urinary tract infection

The regimens are shown together with the number of dosing units required for that regimen. Antibiotics are listed alphabetically by WHO Access or Watch groups with unclassified antibiotics listed separately. Bold font indicates availability of an optimal pack for the listed antibiotic and regimen. Normal font indicates availability of an adequate pack for the listed antibiotic and regimen, meaning that matching could be achieved by adding or dropping a single dosing unit to the regimen or leftovers of < one single dosing unit. Listed regimens represent $36.6 \%$ (15/42 regimens) in this weight-example. All remaining regimens did not have matching optimal or adequate packs 
Table 5 Pack-antibiotic regimen matching in children (optimal and adequate) weighing $25 \mathrm{~kg}$ ( $\approx 8$ years of age)

\begin{tabular}{|c|c|c|c|c|c|c|c|c|}
\hline \multicolumn{4}{|l|}{ Regimen } & \multirow[t]{2}{*}{ CAP } & \multirow{2}{*}{$\begin{array}{l}\text { Otitis } \\
\text { media }\end{array}$} & \multirow[t]{2}{*}{ Tonsillopharyngitis } & \multirow[t]{2}{*}{ Sinusitis } & \multirow{2}{*}{$\begin{array}{l}\text { Afebrile } \\
\text { UTI }\end{array}$} \\
\hline Substance & Single dose & $\mathrm{N}$ doses/day & Duration (in days) & & & & & \\
\hline \multicolumn{9}{|l|}{ WHO group: ACCESS } \\
\hline \multirow[t]{2}{*}{ Amoxicillin } & $40 \mathrm{mg} / \mathrm{kg}$ & 2 & 5 & 2 & & & & \\
\hline & $40 \mathrm{mg} / \mathrm{kg}$ & 2 & 7 & $2.8(+1)$ & & & & \\
\hline \multirow[t]{2}{*}{ Amoxicillin/clavulanate } & 26.7 mg/kg & 3 & 5 & & & & & $0.89(+1)$ \\
\hline & 40 mg/kg & 2 & 5 & $0.89(+1)$ & $0.89(+1)^{\mathbf{a}}$ & & & $0.89(+1)$ \\
\hline \multirow[t]{2}{*}{ Cotrimoxazole } & $18 \mathrm{mg} / \mathrm{kg}$ & 2 & 5 & & 0.94 & & & 0.94 \\
\hline & $18 \mathrm{mg} / \mathrm{kg}$ & 2 & 10 & & $1.88(+1)$ & & & \\
\hline \multicolumn{9}{|l|}{ WHO group: WATCH } \\
\hline \multirow[t]{2}{*}{ Azithromycin } & 10 mg/kg & 1 & 3 & $1.25(-1)$ & $1.25(-1)$ & & & \\
\hline & 10 mg/kg & 1 & 5 & & & $1.04(-1)$ & & \\
\hline \multicolumn{9}{|c|}{ WHO group: UNCLASSIFIED } \\
\hline \multirow[t]{2}{*}{ Cefuroxime } & $15 \mathrm{mg} / \mathrm{kg}$ & 2 & 7 & 3 & & & & \\
\hline & $15 \mathrm{mg} / \mathrm{kg}$ & 2 & 14 & & & & $6^{\mathrm{a}}$ & \\
\hline
\end{tabular}

a part of the SSI-Guidelines (ssi.guidelines.ch)

$+1=$ optimized by adding a single dose; $-1=$ optimized by subtracting a single dose

CAP Community-acquired pneumonia, UTI Urinary tract infection

The regimens are shown together with the number of dosing units required for that regimen. Antibiotics are listed alphabetically by WHO Access or Watch groups with unclassified antibiotics listed separately. Bold font indicates availability of an optimal pack for the listed antibiotic and regimen. Normal font indicates availability of an adequate pack for the listed antibiotic and regimen, meaning that matching could be achieved by adding or dropping a single dosing unit to the regimen or leftovers of < one single dosing unit. Listed regimens represent $24.4 \%$ (10/42 regimens) in this weight-example. All remaining regimens did not have matching optimal or adequate packs

For children very low rates of suitable packs were available. Moving from exact weight-based to weight-banded dosing with appropriate packs, and greater advocacy for the development and licensing of dispersible or minitablets could mitigate some of the specific challenges [19, 22]. Indeed, despite the current situation, use of childappropriate formulations of Access antibiotics in Switzerland is high (> 85\%) [23]. Packs often seem adapted to cater to older (and heavier) children and longer treatment durations with poorer compliance [24]. Considering they experience the highest rates of community-based antibiotic prescribing, the fewest suitable packs for evidence-based shorter treatment durations were available for children less than 5 years of age [23]. In contrast, some regimens could only be achieved by dispensing multiple packs, increasing the risk that a second package is not administered and kept at home for future use as well as of environmental contamination on disposal.

Similar mismatches between recommended regimens and available pack sizes have been documented in Croatia, India and Australia, with this phenomenon thought to account for a substantial proportion of "redundant antibiotic doses in the community" $[6,8,9]$. Antibiotics dispensed in fixed packs seem to be a risk factor for leftovers in adults. Kardas and colleagues describe a higher tendency for patients in "pack-countries" to save leftovers or give them to others than in "pillcountries" where the exact amount of pills required per course is dispensed [5]. Leftover antibiotics are also often disposed in the household waste or flushed down the toilet which can contribute to the development of antibiotic resistance [25].

The strength of our study is that we most likely were able to identify the majority of frequently used regimens for five infections commonly managed in primary care and combined these with comprehensive information on available antibiotic packs in Switzerland. Furthermore, we covered the whole population of adults and children in our analysis. We anticipate that our observations will be applicable to many other pack-dispensing countries.

Our study also has limitations. We focused on hospital guidelines and very recent national recommendations. In general, all community prescribers in Switzerland will undergo hospital-based training, and current prescribers will most likely have been exposed to hospital antibiotic policies during their training [26, 27]. We also selected certain infections based on their considerable contribution to antibiotic prescribing in the community. Antibiotics and treatment regimens may differ for other common infections, such as skin and soft tissue infections, with potentially better matching with available packs. When treatment ranges were given, we only considered the minimal and maximal duration, but durations in between may also be chosen. In certain cases, such an intermediate duration could provide an optimal or adequate match with an available pack. Of note, some intermediate durations may actually have been represented in another included recommendation. We 
incorporated the regimens with one missing single dose in the adequate match group because we considered one missing dose of a regimen to be clinically acceptable. However, this could be result in the dispensation of an additional full pack and increase the risk of leftover antibiotics. In children, we analysed only four weight examples and sometimes slightly higher or lower weight may achieve good matching. This makes an exact evaluation complex, as leftover dose units will differ by weight. It also demonstrates the potential negative impact of exact weight-based dosing using suspensions on matching of treatment recommendations and available pack sizes. Finally, even with perfect matching of available packs and treatment regimens adherence may be suboptimal and doses may be left over.

\section{Conclusions}

This study highlights that fixed packs of antibiotics in Switzerland often do not fit with the recommended treatment regimens. Influencing pack sizes to ensure that optimal packs for shortest evidence-based regimens are available is challenging, with complex economic and regulatory implications. Furthermore, the same antibiotics are likely to be used differently for the treatment of different infections. As part of national stewardship efforts, consideration should therefore be given to moving to an exact pill-count system for adults and advocating for weight-banded dosing approaches or childappropriate solid formulations for children. Exact pillcount dispensation in particular would support wider use of short Access antibiotic treatment courses and could enable personalised treatment regimens based on stratification factors in the future.

\section{Supplementary information}

Supplementary information accompanies this paper at https://doi.org/10. 1186/s13756-020-00724-7.

Additional file 1. Sources of Guidelines. Source hospitals providing guidelines used as basis for the study.

Additional file 2. Guidelines and pack size matching. Availability of optimal, adequate and no matching pack sizes for all relevant antibiotics but not specific to indication. Data are shown separately for adults (Table 2a) and children (Table 2b)

Additional file 3. Available formulations in Switzerland for quidelinerelevant antibiotics. Available formulations shown by beta-lactams (Table 3a), quinolones (Table 3b) and other antibiotics (Table 3c); both solid and liquid formulations were included.

Additional file 4. Guidelines and pack size matching according to the WHO AWaRe groups. Data are shown separately for adults (Table 4a) and children (Table 4b).

\section{Abbreviations}

AWaRe: Access, Watch, Reserve; CAP: Community-acquired pneumonia; UTI: Urinary tract infections; WHO: World Health Organisation

\section{Authors' contributions}

JF, JAB and AW designed the study. JF and DB collected the data. JF conducted the data analysis under JAB's supervision, and wrote a first draft of the manuscript. All authors critically revised the manuscript, and have read and approved the final version.

Authors' information

Not applicable.

Funding

No specific funding was received for conducting the presented research.

Availability of data and materials

The datasets used and/or analysed during the current study are available from the corresponding author on reasonable request.

Ethics approval and consent to participate

Not applicable.

\section{Consent for publication}

Not applicable.

\section{Competing interests}

JAB's husband is a senior corporate counsel at Novartis International AG (Basel, Switzerland) and holds Novartis stock and stock options. All other authors declare no competing interests.

\section{Author details}

1Division of Infectious Diseases and Hospital Epidemiology, University Hospital Basel, Petersgraben 4, 4031 Basel, Switzerland. ${ }^{2}$ Paediatric Pharmacology Group, University of Basel Children's Hospital, Basel, Switzerland. ${ }^{3}$ SwissNoso, National Centre for Infection Prevention, Bern, Switzerland. ${ }^{4}$ Hospital Pharmacy, University Hospital Basel, Basel, Switzerland. ${ }^{5}$ Division of Infectious Diseases and Hospital Epidemiology, University Children's Hospital Zurich, Zurich, Switzerland. ${ }^{6}$ Children's Research Center, University Children's Hospital Zurich, Zurich, Switzerland. 'Infection Control Program and Division of Infectious Diseases, World Health Organization Collaborating Centre on Patient Safety, Geneva University Hospitals, Geneva, Switzerland. ${ }^{8}$ Faculty of Medicine, University of Geneva, Geneva, Switzerland.

Received: 22 January 2020 Accepted: 28 April 2020

Published online: 08 May 2020

References

1. Laxminarayan R, Duse A, Wattal C, AKM Z, HFL W, Sumpradit N, et al. Antibiotic resistance-the need for global solutions. Lancet Infect Dis. 2013; 13(12):1057.

2. Khalifeh MM, Moore ND, Salameh PR. Self-medication misuse in the Middle East: a systematic literature review. Pharmacol Res Perspect. 2017;5(4):1-13.

3. Ocan M, Obuku EA, Bwanga F, Akena D, Richard S, Ogwal-Okeng J, et al. Household antimicrobial self-medication: a systematic review and metaanalysis of the burden, risk factors and outcomes in developing countries. BMC Public Health. 2015;15(1):742 Available from: http://bmcpublichealth. biomedcentral.com/articles/10.1186/s12889-015-2109-3.

4. Shehnaz SI, Agarwal AK, Khan N. A systematic review of self-medication practices among adolescents. J Adolesc Health. 2014;55(4):467-83. https:// doi.org/10.1016/j.jadohealth.2014.07.001.

5. Kardas P, Pechère JC, Hughes DA, Cornaglia G. A global survey of antibiotic leftovers in the outpatient setting. Int J Antimicrob Agents. 2007;30(6):530-6.

6. McGuire TM, Smith J, Del Mar C. The match between common antibiotics packaging and guidelines for their use in Australia. Aust N Z J Public Health. 2015;39(6):569-72.

7. TM MG. Does size matter? Addressing pack size and antibiotic duration. Aust Prescr. 2019;42(1):2 [Cited 2019 Apr 18]. Available from: http://www. ncbi.nlm.nih.gov/pubmed/30765900.

8. Mukherjee S, Nilanjan S. Correlation of recommendations of treatment guidelines and frequently prescribed antibiotics: evaluation of their pharmaceutical pack size. Basic Clin Pharmacol Toxicol. 2017;12(10):3218-21.

9. Rusic D, Bozic J, Bukic J, Seselja Perisin A, Leskur D, Modun D, et al. Evaluation of accordance of antibiotics package size with recommended 
treatment duration of guidelines for sore throat and urinary tract infections. Antimicrob Resist Infect Control. 2019;8:30 [Cited 2020 Mar 27]. Available from: http://www.ncbi.nlm.nih.gov/pubmed/30792852.

10. Llewelyn MJ, Fitzpatrick JM, Darwin E, Sarahtonkin-Crine GC, Paul J, et al. The antibiotic course has had its day. BMJ. 2017;358:1.

11. Sharland M, Pulcini C, Harbarth S, Zeng M, Gandra S, Mathur S, et al. Classifying antibiotics in the WHO essential medicines list for optimal use - be AWaRe. Lancet Infect Dis. 2018;18(1):18.

12. Home | AWaRe. [cited 2019 Aug 8]. Available from: https://adoptaware.org/.

13. Geli P, Laxminarayan R, Dunne M, Smith DL. 'One-size-fits-all'? Optimizing treatment duration for bacterial infections. PLoS One. 2012;7:1.

14. Federal Office of Public Health (FOPH). Health insurance: The Essentials in Brief. [Cited 2019 Apr 14]. Available from: https://www.bag.admin.ch/bag/ en/home/versicherungen/krankenversicherung/krankenversicherung-daswichtigste-in-kuerze.html.

15. Federal Office of Public Health (FOPH). Your questions, our answers. OfficePro. 2011;71(2):30 Available from: http://search.ebscohost.com/login. aspx?direct=true\&db=bth\&AN=59242446\&site=ehost-live.

16. Federal Office of Public Health FOPH. Information related to the specialities list [Internet]. [cited 2019 Apr 14]. Available from: https://www.bag.admin. ch/bag/en/home/versicherungen/krankenversicherung/ krankenversicherung-leistungen-tarife/Arzneimittel/Mitteilungen-zurSpezialitaetenliste.html.

17. Concept for the development of Clinical Guidelines for the SSI [Internet] [cited 2019 Jan 17]. Available from: http://www.sginf.ch/files/star-guidelines_ concept.pdf.

18. compendium.ch [Internet]. [cited 2017 Aug 21]. Available from: https:// www.compendium.ch/home/de.

19. Van Riet-Nales DA, AFAM S, Vromans H, TCG E, CMA R. Safe and effective pharmacotherapy in infants and preschool children: importance of formulation aspects. Arch Dis Child. 2016;101:662-9.

20. Harris PA, Taylor R, Thielke R, Payne J, Gonzalez N, Conde JG. Research electronic data capture (REDCap)--a metadata-driven methodology and workflow process for providing translational research informatics support. J Biomed Inform. 2009;42(2):377-81 [Cited 2019 Jul 12]. Available from: http:// www.ncbi.nlm.nih.gov/pubmed/18929686.

21. Wachstumskurven A, Braegger C, Jenni O, Konrad D, Verantwortung R, Molinari L. Neue Wachstumskurven für die Schweiz. Paediatrica. 2011;22, 9(1).

22. Bielicki JA, CIS B, Saxena S, ICK W, Long PF, Sharland M. Not too little, not too much: problems of selecting oral antibiotic dose for children. BMJ. 2015;5447: h5447 Available from: http://www.bmj.com/lookup/doi/10.1136/bmj.h5447.

23. Hsia Y, Sharland M, Jackson C, Wong ICK, Magrini N, Bielicki JA. Consumption of oral antibiotic formulations for young children according to the WHO access, Watch, reserve (AWaRe) antibiotic groups: an analysis of sales data from 70 middle-income and high-income countries. Lancet Infect Dis. 2019;19(1):67-75 [Cited 2019 Jan 13]. Available from: http://www.ncbi. nlm.nih.gov/pubmed/30522834.

24. Hoppe JE, Blumenstock G, Grotz W, Selbmann HK. Compliance of German pediatric patients with oral antibiotic therapy: results of a nationwide survey. Pediatr Infect Dis J. 1999;18(12):1085.

25. Mispagel H, Gray JT. Antibiotic resistance from wastewater oxidation ponds. Water Environ Res. 2005;77(7):2996-3002 [Cited 2020 Mar 27]. Available from: http://doi.wiley.com/10.2175/106143005X73875.

26. Osthoff M, Bielicki J, Widmer AF-X. Swissnoso for. Evaluation of existing and desired antimicrobial stewardship activities and strategies in Swiss hospitals. Swiss Med Wkly. 2017;147:4142 [Cited 2018 Sep 6]. Available from: http:// doi.emh.ch/smw.2017.14512.

27. Charani E, Castro-Sanchéz E, Bradley S, Nathwani D, Holmes AH, Davey P. Implementation of antibiotic stewardship in different settings - results of an international survey. Antimicrob Resist Infect Control. 2019;8(1):34 [Cited 2019 Aug 8]. Available from: https://aricjournal.biomedcentral.com/articles/1 0.1186/s13756-019-0493-7.

\section{Publisher's Note}

Springer Nature remains neutral with regard to jurisdictional claims in published maps and institutional affiliations.

\section{Ready to submit your research? Choose BMC and benefit from:}

- fast, convenient online submission

- thorough peer review by experienced researchers in your field

- rapid publication on acceptance

- support for research data, including large and complex data types

- gold Open Access which fosters wider collaboration and increased citations

- maximum visibility for your research: over $100 \mathrm{M}$ website views per year

At BMC, research is always in progress.

Learn more biomedcentral.com/submissions 